\title{
Autoimmune liver disease-associated serologic profiling in Chinese patients with acute hepatitis E virus infection
}

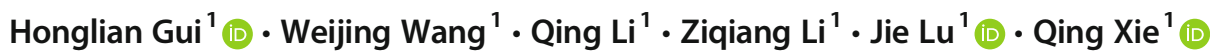

Received: 31 July 2020 / Accepted: 18 January 2021 / Published online: 28 January 2021

(C) The Author(s) 2021

\begin{abstract}
The association between hepatitis E virus (HEV) and autoimmune liver diseases has been well-researched; however, the focus has been on autoimmune hepatitis (AIH) and not primary biliary cholangitis (PBC). Therefore, we aimed to investigate the prevalence and evolution of AIH- and PBC-related autoantibodies in Chinese patients with HEV infection. In this retrospective study, 164 patients with acute HEV were included, specifically those whose liver autoantibody results were available and who had no pre-existing liver disease at the time of HEV diagnosis. Positive liver autoimmune serology was present in 69 (42.1\%) patients and $21(12.8 \%)$ had at least two autoantibodies at diagnosis. Greater age and alkaline phosphatase levels were independent risk factors for autoantibody positivity. Follow-up serologic tests, which were available for 27 of the 69 autoantibodypositive patients, showed that although antinuclear antibodies disappeared in 11/20 (55.0\%) and antimitochondrial antibodies disappeared in 4/5 (80\%) patients, 16 still remained positive for autoantibodies and two of them even developed new PBC-related antibodies, as described below. One patient developed a rim-like ANA pattern, accompanied by an enhancement of anti-gp210 positivity; and the other was diagnosed as $\mathrm{PBC}$, based on chronic elevation of cholestatic enzymes and presentation with de novo AMA-M2, 18 months after HEV clearance. In conclusion, AIH- and PBC-related autoantibodies are frequently present during acute HEV infection, indicating that HEV should be excluded before diagnosing AIH and/or PBC. Importantly, some cases maintained or developed autoantibodies after viral clearance, and one patient subsequently developed PBC, highlighting that these individuals warrant long-term follow-up.
\end{abstract}

Keywords Autoimmune hepatitis $\cdot$ Autoantibody $\cdot$ Hepatitis E virus $\cdot$ Liver function $\cdot$ Primary biliary cholangitis

\section{Introduction}

Autoimmune hepatitis (AIH) and primary biliary cholangitis (PBC), two major autoimmune liver diseases, are usually lifethreatening when left untreated. Thus, early and reliable diagnoses are paramount for the initiation of appropriate therapy. A detailed characterization of autoantibody specificities and titers is indispensable for the diagnosis of these diseases [1]. In general, the presence of antinuclear antibodies (ANA) and

Honglian Gui and Weijing Wang contributed equally to this work.

$\mathrm{Jie} \mathrm{Lu}$

jessielu1978@163.com

Qing Xie

xieqingrjh@163.com

1 Department of Infectious Diseases, Ruijin Hospital, Shanghai Jiao Tong University School of Medicine, Shanghai 200025, China anti-smooth muscle antibodies (SMA) are characteristic of AIH-1 [2], while anti-mitochondrial autoantibodies (AMA) or PBC-specific ANA (mainly including anti-gp210 and anti-sp 100) are characteristic of PBC [3].

To date, the etiology of these autoimmune liver diseases has been poorly understood. In addition to genetic predisposition, specific environmental factors have been considered to be triggers for the initiation and/or acceleration of autoimmune processes; these include medications, vaccinations, and infections [4, 5]. Hepatitis viruses that cause direct liver damage have naturally been suspects for the etiology of these diseases. Hepatitis $\mathrm{C}$ virus (HCV) has been closely associated with the development of AIH [4, 6, 7].

Hepatitis E, an infectious disease caused by the hepatitis E virus (HEV), has worldwide prevalence [8]. HEV has extensive genetic diversity: HEV genotype (GT)-1 and GT-2 infections are waterborne and causative for epidemics in the tropics, while GT3 and GT-4 infections are sporadic zoonotic diseases and are mainly transmitted by ingestion of undercooked food [9-11]. 
The clinical course of these infections differs. GT-1 and GT-2 infections are generally self-limiting and can lead to liver failure with high mortality in pregnant women, while the majority of GT-3 and GT-4 infections have a clinically asymptomatic course and can only cause severe hepatitis and liver failure in the elderly or in patients with underlying liver disease [9]. Immunosuppressed individuals infected with GT-3 or GT-4 may develop chronic hepatitis E, which then leads to rapidly progressing liver disease [12].

With more widespread recognition of HEV, a series of studies has focused on the association between HEV infection and autoimmune liver diseases. A higher HEV seroprevalence has been reported in AIH patients in Germany [13] and in Austria [14], but not in the Netherlands [15], probably due to the fairly high HEV incidence in the latter. Furthermore, some autoantibodies that are typically found in patients with AIH have also been reported in acute hepatitis E patients in Europe, America, and Asia [16-21]. Similarly, the prevalence of anti-HEV antibodies in patients with $\mathrm{PBC}$ has also been controversial $[22,23]$. Few studies have addressed the presence of PBC-related autoantibodies in patients with acute hepatitis E. One case, positive for both HEV RNA and antiAMA-M2, was diagnosed as acute HEV infection and confirmed as PBC by liver biopsy [24]. The association between HEV infection and PBC has not been firmly established. Therefore, the aim of the present study was to investigate the prevalence and evolution of AIH- and PBC-related autoantibodies in a well-characterized cohort of Chinese patients with acute HEV infection.

\section{Patients and methods}

The study was conducted in accordance with ethical guidelines of the Declaration of Helsinki 1975 and was approved by the ethics committee of Shanghai Ruijin Hospital (No.2019251). Written informed consent was exempted on account of retrospective nature of this study.

\section{Study population}

We retrospectively collected information from all consecutive hospitalized patients with acute HEV infection diagnosed at Ruijin Hospital between January 2016 and August 2019. The inclusion criteria were (i) positive HEV RNA in serum and/or serum positive for a combination of anti-HEV IgM and IgG and (ii) liver autoantibody results available at the time of HEV diagnosis. Most patients were diagnosed by HEV serology, since HEV RNA assays had not been used in our hospital until August 2018. No time had elapsed between HEV diagnosis and autoantibody testing, since differential diagnosis was needed immediately for all patients with acute hepatitis of unknown origin. Given that some autoantibodies are not disease-specific and are present in other liver diseases [1], patients with any pre-existing liver disease, including alcoholic/non-alcoholic fatty liver disease (AFLD/NAFLD), chronic hepatitis $\mathrm{B}$ and/or hepatitis $\mathrm{C}$, autoimmune liver diseases, and schistosomiasis liver disease, were excluded from the study.

\section{Study design}

All data (demographic, biochemical, and serological features) were extracted from the hospital electronic patient database. Clinical information included age, sex, and history of autoimmune disease, immunosuppression, current malignancies, and pre-existing liver disease. To better represent the severity of disease, the following biochemical data were included: the earliest available alanine aminotransferase (ALT), aspartate aminotransferase (AST), alkaline phosphatase (ALP), and gamma-glutamyl transpeptidase (GGT) levels were recorded, as were the highest available total bilirubin and international normalized ratio (INR) levels, during the whole course of disease. The circulating autoantibodies including AMA, M2, anti-gp210, anti-sp100, ANA, SMA, anti-neutrophil cytoplasmic antibody (ANCA), anti-soluble liver antigen/liverpancreas antibody (SLA/LP), anti-liver cytosol type 1 antibody (LC-1), and anti-liver-kidney microsomal type 1 antibody (LKM-1) were tested. The follow-up autoantibody and liver function tests, as initiated by the outpatient physicians, were performed using the same methodology as tests at presentation.

\section{Laboratory assessment}

Indirect immunofluorescence assays (IIF) on rat kidney, liver, and stomach tissue (Euroimmun) were performed for detection of liver autoantibodies, and a titer of 1:100 was defined as a positive reaction according to the recommendation of the assay kits. IIF on human epithelial type 2 (HEp2) cells (INOVA) was used for ANA titer determination and pattern definition; its recommended minimum dilution is 1:40 (1:40, 1:80, 1:160, 1:320, etc.). Immunoblotting (with Euroline Liver-Profile $4 \mathrm{IgG}$ from Euroimmun) was performed for SLA/LP, LC-1, LKM-1, anti-sp100, anti-gp210, and antiM2 antibodies. ANCA was tested by IIF on human granulocytes (Euroimmun), and a titer of 1:10, 1:32, or $\geq$ 1:100 was defined as a week-positive, positive or strongpositive reaction, respectively; any reactivity was further analyzed using anti-proteinase 3 and anti-myeloperoxidase ELISA kits (Euroimmun). Detection of IgG and IgM HEVspecific antibodies was performed using Wantai HEV ELISA kits. HEV RNA was detected with the Promotor ${ }^{\circledR}$ HEV RNA detection kit (ACON). Serum total immunoglobulin concentrations (including $\operatorname{IgG}, \operatorname{IgM}, \operatorname{IgA}$, and $\operatorname{IgE}$ ) were assessed by 
immunonephelometry. All assays were performed according to the manufacturer's instructions.

\section{Statistics}

Statistical analysis was performed with IBM SPSS 23 for Windows. Continuous variables were presented as medians (interquartile range, IQR) and compared using MannWhitney test. Frequency data were expressed as numbers and percentages and compared using Fisher's exact test. Variables with a $p<0.1$ in univariate analysis were further analyzed in multivariate analysis performed by binary logistic regression, with odds ratio (OR) and $95 \%$ confidence interval (CI) calculated. $p$ values $\leq 0.05$ (two-sided) were considered to be statistically significant.

\section{Results}

\section{Overview of study population}

A total of 361 adult patients were diagnosed with acute HEV infection between January 2016 and August 2019, of whom 197 patients were excluded due to the presence of other preexisting liver diseases or incomplete data on autoantibodies (Fig. 1). The remaining 164 patients met the inclusion criteria, with $93(56.7 \%)$ males and median age at HEV infection of 54 years (range, 25-82). All patients were positive for anti-HEV IgM; HEV RNA was also detected in the serum of 58 patients out of the 62 who were tested. HEV genotyping was successful in $72 \%$ of PCR-positive samples (42/58) - 29 were classified as $4 d$, nine were $4 b$, and one each were $3 b, 4 a, 4 h$, and $4 \mathrm{i}$ infections.

Negative HEV RNA results were obtained in all 42 patients who tested positive while in hospital. Notably, eleven patients were taking immunosuppressive drugs at the time of HEV diagnosis, and none of them developed chronic HEV infection: four because of breast cancer (two received epirubicin plus cyclophosphamide; the other two received Herceptin plus docetaxel) and one each because of membranous nephropathy (methylprednisolone plus tacrolimus), nasopharyngeal carcinoma (cisplatin plus 5-fluorouracil, and daily radiation), Behcet's disease (hydroxychloroquine plus methotrexate), ankylosing spondylitis (recombinant human type II tumor necrosis factor receptor antibody fusion protein for injection $50 \mathrm{mg} /$ month), sicca syndrome (methylprednisolone $2 \mathrm{mg}$ /day), ANCA-associated nephritis (prednisone $30 \mathrm{mg} /$ day), and cutaneous amyloidosis (methylprednisolone $24 \mathrm{mg}$ /day). None of them developed chronic HEV infection and were treated with ribavirin.

Among the 164 patients included in the study, none were treated with ribavirin throughout the course of HEV infection. None underwent a liver biopsy, since the cause of the acute hepatitis was clear, and all patients recovered, except two died during treatment for HEV infection because of complications of severe pulmonary infection and complex abdominal infection, respectively. The other patients had normal liver biochemistry results either when at discharge or at outpatient follow-up within 2 to 4 weeks after discharge (Table 1). Only one patient was re-admitted for persistent liver disease
Fig. 1 Flow chart illustrating the design

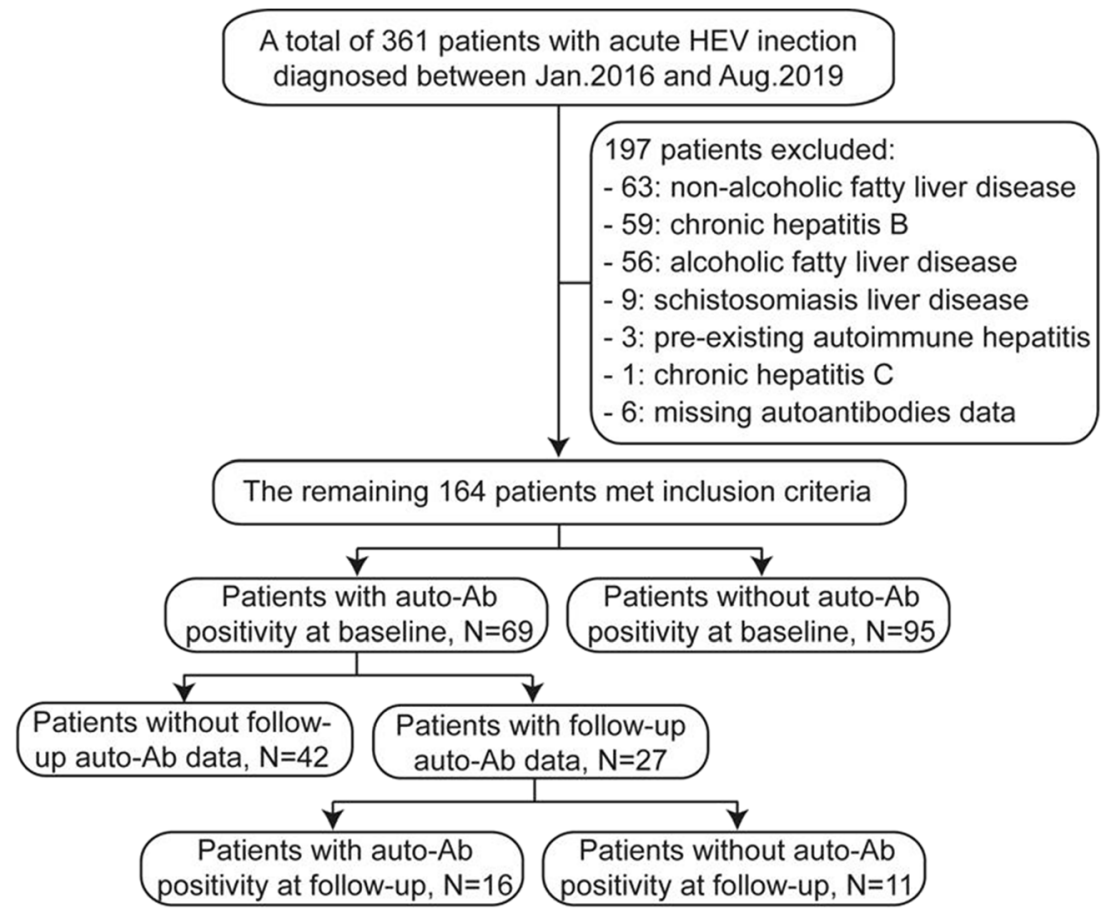


Table 1 Characteristics of patients presenting with or without autoantibodies

\begin{tabular}{|c|c|c|c|}
\hline & $\begin{array}{l}\text { Auto-Abs(+) group } \\
\text { at baseline, } n=69\end{array}$ & $\begin{array}{l}\text { Auto-Abs(-) group } \\
\text { at baseline, } n=95\end{array}$ & $p$ \\
\hline Female, $n(\%)$ & $33(47.8)$ & $38(40.0)$ & 0.318 \\
\hline Age, y, median (IQR) & $61(50-67)$ & $52(38-61)$ & 0.001 \\
\hline Past/current cancer, $n(\%)$ & $4(5.8)$ & $7(7.4)$ & 0.691 \\
\hline Concomitant autoimmune diseases, $n(\%)$ & $11(15.9)$ & $6(6.3)$ & 0.046 \\
\hline Immunosuppressive treatment, $n(\%)$ & $5(7.2)$ & $6(6.3)$ & 0.814 \\
\hline \multicolumn{4}{|l|}{ Baseline parameters, median (IQR) } \\
\hline ALT, $\times$ ULN & $31.5(18.2-43.1)$ & $30.5(16.2-44.9)$ & 0.794 \\
\hline AST, $\times$ ULN & $30.2(13.8-45.5)$ & $25.8(10.6-45.8)$ & 0.289 \\
\hline ALP,$\times U L N$ & $1.6(1.2-1.8)$ & $1.3(1.1-1.7)$ & 0.009 \\
\hline GGT, $\times$ ULN & $3.1(2.2-5.0)$ & $2.9(1.6-4.5)$ & 0.187 \\
\hline Total bilirubin, $\times$ ULN & $6.4(3.5-12.6)$ & $5.0(1.6-10.3)$ & 0.105 \\
\hline $\begin{array}{l}<2 \times \mathrm{ULN}, n(\%) \\
\geq 2 \times \mathrm{ULN}, n(\%)\end{array}$ & $\begin{array}{l}6(8.7) \\
63(91.3)\end{array}$ & $\begin{array}{l}25(26.3) \\
70(73.7)\end{array}$ & 0.004 \\
\hline $\mathrm{INR}^{\dagger}$ & $1.04(0.96-1.23)$ & $1.03(0.93-1.17)$ & 0.495 \\
\hline Serum IgG, mg/dL & $1475(1285-1845)$ & $1320(1190-1550)$ & 0.006 \\
\hline Serum IgA, mg/dL & $267(216-351)$ & $241(196-339)$ & 0.095 \\
\hline Serum IgM, mg/dL & $254(158-375)$ & $195(137-282)$ & 0.027 \\
\hline Serum IgE, IU/mL & $82(30-202)$ & $42(17-123)$ & 0.020 \\
\hline HEV genotype, $n$ & 19 & 23 & \\
\hline $3 \mathrm{~b} / 4 \mathrm{a} / 4 \mathrm{~b} / 4 \mathrm{~d} / 4 \mathrm{~h} / 4 \mathrm{i}, n$ & $0 / 1 / 3 / 14 / 1 / 0$ & $1 / 0 / 6 / 15 / 0 / 1$ & 0.543 \\
\hline \multicolumn{4}{|l|}{ Follow-up parameters, median (IQR)* } \\
\hline $\mathrm{ALT}, \times \mathrm{ULN}$ & $0.3(0.2-0.4)$ & $0.3(0.3-0.5)$ & 0.078 \\
\hline AST, $\times$ ULN & $0.6(0.5-0.7)$ & $0.6(0.5-0.7)$ & 0.109 \\
\hline ALP,$\times U L N$ & $0.7(0.5-0.8)$ & $0.6(0.5-0.7)$ & 0.748 \\
\hline GGT, $\times$ ULN & $0.5(0.3-0.7)$ & $0.5(0.3-0.8)$ & 0.748 \\
\hline Total bilirubin, $\times$ ULN & $0.8(0.6-0.9)$ & $0.8(0.7-1.0)$ & 0.142 \\
\hline
\end{tabular}

${ }^{\dagger}$ Two patients were excluded because of taking anticoagulant warfarin

* Two patients were excluded due to death

$A L T$ alanine aminotransferase, $A L P$ alkaline phosphatase, $A S T$ aspartate aminotransferase, $H E V$ hepatitis $\mathrm{E}$ virus, $I g$ immunoglobulin, INR International Normalized Ratio, IQR interquartile range, GGT gamma-glutamyl transpeptidase, $U L N$ upper limit of normal
1.5 years later (described below). No patient was treated with immunosuppressive therapy later since no definitive diagnosis of AIH was made over a short follow-up period in our series.

\section{Liver autoimmune serology at acute HEV infection}

Positive liver autoimmune serology was present in $69(42.1 \%)$ of the patients at the time of acute HEV infection, and 21 $(12.8 \%)$ had two or more autoantibodies detected.

AIH-associated autoantibodies were detected in 63 patients (Fig. 2a). ANA tests were positive in 50 patients (30.5\%), with titers ranging from 1:80 to 1:320 (22 multiple nuclear dots (MND), 11 speckled, eight homogeneous, four nucleolar, and five mixed patterns). SMA was positive in nine patients (5.5\%). Two patients $(1.2 \%)$ had positive immunoblotting for anti-LC1: one case was a 36-year-old male with anti-LC1 as the only serological marker; the other was a 56-year-old female, accompanied by mixed IIF pattern for ANA and positive immunoblotting for anti-gp210 and anti-sp100, with rapid normalization of the transaminase levels. Anti-SLA and LKM1 were negative in all patients. P-ANCA was detected in 18 patients (13 weakly positive, four positive, one strongly positive) and appeared alone in eight patients, alongside ANA in nine, and together with both ANA and SMA in one. Sera positive for ANCA at IIF on human granulocytes did not react with any of the main molecular ANCA targets as assessed by ELISAs.

PBC-associated autoantibodies were detected in 15 patients (Fig. 2b). IIF-AMA positivity on triple rodent tissue was detected in 10 patients $(6.1 \%)$; of whom 3 were M2 subtype positive when tested by immunoblotting, while the 7 remaining were negative when tested by immunoblotting, showing an atypical AMA-positive immunofluorescence, but negative immunoblot. Anti-gp210 was detected in 6 
Fig. 2 Numbers of acute hepatitis E patients with positive $\mathrm{AIH}$ - or PBC-associated autoantibodies. Patients were positive for one or more of the following antibodies: a $\mathrm{AIH}$-associated autoantibodies; b PBC-associated autoantibodies, detected at the time of acute HEV infection. ${ }^{\dagger}$ One patient each presented with M2-subtype positivity; ${ }^{*}$ nine patients had antibodies for both $\mathrm{AIH}$ and $\mathrm{PBC}$

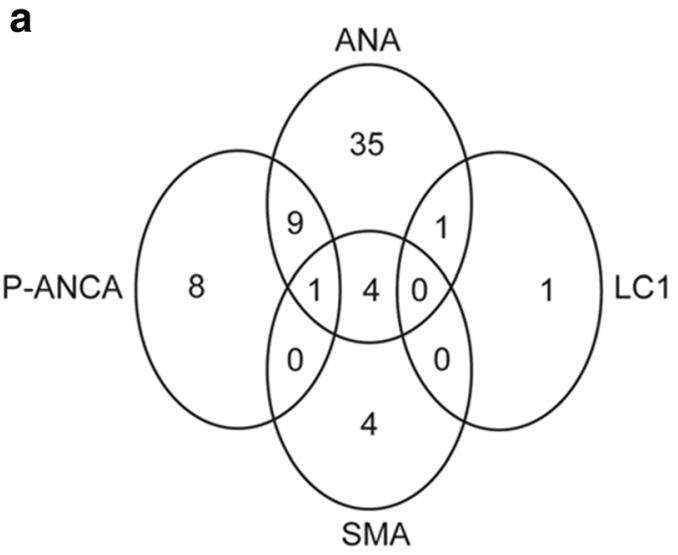

b

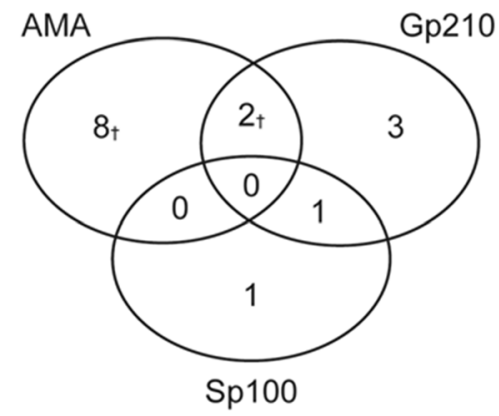

patients (two positive, four weakly positive); 5 of them were also positive for ANA (1 homogeneous, 2 speckled, and 2 mixed patterns (rim-like accompanied by MND and homogeneous pattern, respectively)). Anti-sp100, another PBCspecific ANA, was present in two patients; both were also positive for ANA (1 MND and 1 mixed patterns). There were nine patients positive for both $\mathrm{AIH}$ - and $\mathrm{PBC}$-related antibodies.

As shown in Table 1, the patients with autoantibody positivity were of a significantly greater age, had more concomitant autoimmune diseases and higher incidence of clinical jaundice, and elevated levels of serum alkaline phosphatase (ALP), IgG, IgM, and IgE than patients with no autoantibody detectable at the time of acute $\mathrm{HEV}$ infection. In a further multivariate analysis, greater age (OR 0.968, 95\% CI: 0.941-0.997, $p=0.030$ ) and ALP levels (OR 0.995, 95\%CI: $0.989-1.000, p=0.043$ ) were independent risk factors for positivity for autoantibodies associated with $\mathrm{AIH}$ and/or $\mathrm{PBC}$ in patients with acute $\mathrm{HEV}$ infection.

\section{Prevalence of autoantibodies at follow-up}

Twenty-seven of the 69 autoantibody-positive patients at the time of acute HEV infection had follow-up data available for autoantibodies. Autoantibodies disappeared in 11 patients at a follow-up of 2 to 6 months, while autoantibodies were still present in the other 16 patients at a median (IQR) 14 (8-18) months of follow-up. As shown in Table 2, the patients whose autoantibodies became negative had higher serum IgE levels at baseline when compared with the patients who had remained positive for autoantibodies at follow-up.

Alterations in autoantibody profiles from baseline to follow-up are shown in Fig. 3. ANA disappeared in 11 of 20 $(55.0 \%$ ) donors ( 6 out of 9 MND, 3 out of 5 speckled, and 2 out of 2 nucleolar); and a rim-like ANA pattern with a titer of 1:80 developed two months after HEV clearance (see case A). In the older female patient, anti-LC1 disappeared 3 months after $\mathrm{HEV}$ clearance, but positivity for PBC-specific ANA anti-sp100 and anti-gp210 remained 1 year after discharge.
Among five patients with AMA IIF positivity, four did not show M2 subtype positive when tested by immunoblotting and became negative after HEV clearance; the other patient with AMA-M2 subtype was still positive 18 months later, but was not associated with biochemical cholestasis. However, one developed de novo AMA-M2 18 months after HEV clearance and was diagnosed with PBC (see case B).

\section{Case presentations}

Case A was a 61-year-old female. She presented weakly positive for anti-gp210 by immunoblotting and negative for ANA at diagnosis with acute hepatitis E. She developed a new antibody, showing a rim-like ANA pattern with a titer of 1:80, accompanied by positive immunoblotting for anti-gp210, 2 months after discharge. She maintained positivity for rimlike ANA and anti-gp210 1 year after discharge, but with no evidence of PBC (lack of symptoms, normal liver enzymes, normal abdomen ultrasound, and liver stiffness).

Case B was a 67-year-old male. He presented with a speckled-like ANA with a titer of 1:80 and negative AMA at diagnosis with acute hepatitis E. After 2 weeks of treatment, he was discharged with normalization of all liver function assays. Liver biochemical tests were normal 6 months after discharge. Liver biochemical tests were abnormal 1 year after discharge (ALT 58 IU/L, AST 59 IU/L, ALP 247 IU/L, GGT $671 \mathrm{IU} / \mathrm{L})$, and a computed tomography scan of the abdomen showed no biliary obstruction. A further 6 months later, he had raised cholestatic enzymes (ALP 358 IU/L, GGT 961 IU/ L), accompanied by the presence of speckled-like ANA with a titer of 1:160, de novo AMA by IIF and M2 by immunoblotting. Finally, he was diagnosed with PBC 1.5 years after $\mathrm{HEV}$ clearance and commenced ursodeoxycholic acid (UDCA, 13$15 \mathrm{mg} / \mathrm{kg} / \mathrm{d}$ ) treatment. However, he had abnormal liver biochemical tests (ALT $18 \mathrm{IU} / \mathrm{L}$, AST $37 \mathrm{IU} / \mathrm{L}$, ALP $235 \mathrm{IU} / \mathrm{L}$, GGT $354 \mathrm{IU} / \mathrm{L}$, and total bilirubin $10.3 \mu \mathrm{mol} / \mathrm{L}$ ) and an inadequate biochemical response to UDCA, according the Paris 2 criteria [25], 12 months after treatment. 
Table 2 Clinical features between two subgroups with different evolution of autoantibodies

\begin{tabular}{llll}
\hline & $\begin{array}{l}\text { Auto-Ab(+) subgroup } \\
\text { at follow-up, } n=16\end{array}$ & $\begin{array}{l}\text { Auto-Ab(-) subgroup } \\
\text { at follow-up, } n=11\end{array}$ & $p$ \\
\hline Female, $n(\%)$ & $9(56.3)$ & $5(45.5)$ & 0.704 \\
Age, $y$, median (IQR) & $61(58-68)$ & $62(41-66)$ & 0.521 \\
Concomitant autoimmune diseases, $n(\%)$ & $5(31.3)$ & $3(27.3)$ & 0.100 \\
Baseline parameters, median (IQR) & & & \\
ALT, $\times$ ULN & $32.6(23.1-42.7)$ & $30.9(19.6-48.8)$ & 0.961 \\
AST, $\times$ ULN & $33.0(18.6-43.5)$ & $43.0(16.8-52.2)$ & 0.730 \\
ALP, $\times$ ULN & $1.6(1.4-1.7)$ & $1.5(1.4-2.1)$ & 0.882 \\
GGT, $\times$ ULN & $3.1(1.9-4.4)$ & $3.1(2.2-4.2)$ & 0.554 \\
Total bilirubin, $\times$ ULN & $6.5(5.4-9.2)$ & $10.0(3.7-12.7)$ & 0.554 \\
INR & $1.02(0.95-1.16)$ & $1.03(0.95-1.14)$ & 0.586 \\
Serum IgG, mg/dL & $1550(1255-1645)$ & $1440(1290-1575)$ & 0.748 \\
Serum IgA, mg/dL & $304(267-346)$ & $302(211-355)$ & 0.537 \\
Serum IgM, mg/dL & $239(175-269)$ & $325(158-356)$ & 0.622 \\
Serum IgE, IU/mL & $39(17-103)$ & $127(66-225)$ & 0.046 \\
Follow-up parameters, median $(\mathrm{IQR})$ & & & \\
ALT, $\times$ ULN & $0.3(0.2-0.4)$ & $0.3(0.2-0.3)$ & 0.334 \\
AST, $\times$ ULN & $0.6(0.5-0.6)$ & $0.5(0.5-0.6)$ & 0.308 \\
ALP, $\times$ ULN & $0.6(0.5-0.8)$ & $0.6(0.5-0.9)$ & 0.980 \\
GGT, $\times$ ULN & $0.3(0.2-0.4)$ & $0.6(0.3-0.7)$ & 0.108 \\
Total bilirubin, $\times$ ULN & $0.7(0.6-0.8)$ & $0.8(0.7-0.9)$ & 0.570 \\
\hline
\end{tabular}

$H E V$ hepatitis E virus, $I Q R$ interquartile range, $A L T$ alanine aminotransferase, $U L N$ upper limit of normal, $A S T$ aspartate aminotransferase, $A L P$ alkaline phosphatase, GGT gamma-glutamyl transpeptidase, INR International Normalized Ratio, Ig immunoglobulin

\section{Discussion}

By analyzing liver autoantibodies in a cohort of adult Chinese patients with acute $\mathrm{HEV}$ infection, our results indicated that a high proportion of hepatitis E patients were positive for AIHand PBC-related autoantibodies at the time of HEV infection. Viral infection may trigger autoimmunity in susceptible individuals. Cross-reactivity between immunogenic viral epitopes and auto-antigens has been characterized for many pathogens $[4,16]$. Clearance of viremia would be expected to be accompanied by disappearance of these cross-reactive autoantibodies, as indeed was seen in a considerable proportion of patients in this study. However, $45 \%$ of ANA-positive and $20 \%$ of AMA-positive patients still remained positive at extended time-points; two patients (case A and B) even developed de novo PBC-related autoantibodies. Early encounter with HCV has been shown to trigger late autoimmune mechanisms [4, 6], which might also be the case for HEV.

Notably, $6.1 \%$ of our patients were positive for AMA, which was higher than reported in other studies [19-21]. Admittedly, it is difficult to ascertain whether AMA positivity was secondary to previously undiagnosed PBC or HEV-mediated seroconversion. In our study, 7 out of 10 AMA-positive patients were not confirmed by molecular testing at presentation; and AMA positivity disappeared in all four cases who had follow-up antibodies after HEV clearance. The atypical AMA had a positive immunofluorescence pattern, and staining revealed that they were present in all renal tubules, gastric parietal cells, and hepatocyte cytoplasm and had a negative immunoblot which is a specific characteristic of AMA in PBC, as was described previously [19]. Atypical AMAs were also not associated with biochemical cholestasis. Transient positivity for atypical AMA might be due to acute liver injury, which usually disappears with the resolution of acute disease [20, 26].

ANA is not specific for AIH or PBC; ANA positivity is still considered as a classification criterion for the diagnosis of autoimmune diseases, used to classify patients with AIH-1. The majority of AIH-1 patients show a homogeneous pattern, and speckled or nucleolar patterns are also encountered, while ANA with either MND or rim-like membranous pattern are highly specific for PBC [2]. In our study, homogeneous pattern, which only accounted for a small part of ANA positivity, persisted. Surprisingly, MND was the most frequent ANA pattern, with only two confirmed by anti-sp100 immunoblotting; $2 / 3$ of them then disappeared at follow-up. In fact, MND, differentiated by anti-sp100, can also be found in other diseases, e.g., rheumatological and other connective tissue disorders, while anti-sp100 is much more specific for PBC [27, 28]. The exact reason for the high number of patients with ANA MND pattern is unclear and worthy of further investigations. 


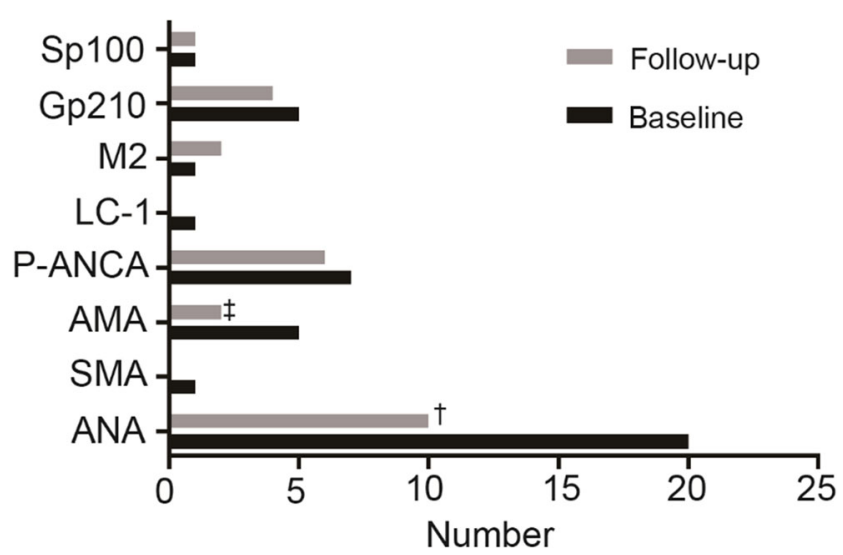

Fig. 3 Alteration of autoantibody profiles from baseline to follow-up. One patient developed a rim-like ANA pattern, so ANA actually disappeared in 11 of $20(55.0 \%)$; ${ }^{*}$ one patient developed de novo AMA, so AMA actually disappeared in 4 of $5(80.0 \%)$

Of note, a high proportion of AMA and/or PBC-specific ANA-positive patients with normal liver enzymes have been shown to have liver pathology consistent with PBC and to ultimately progress over time to develop overt clinical and biochemical features of PBC $[3,29,30]$. As mentioned, the diagnosis of $\mathrm{PBC}$ requires at least two out of the three criteria - specific autoantibody, elevated cholestatic enzymes, and histological findings [3]. Because histological diagnosis was missing for some patients with AMA and/or PBC-specific ANA seropositivity, the possibility exists that the patient who ultimately developed $\mathrm{PBC}$ was already progressing towards $\mathrm{PBC}$ before or at the time of $\mathrm{HEV}$ infection. We were unable to establish an association of PBC with HEV infection, as only one or two patients developed de novo autoantibodies after HEV resolution. However, the presence of HEV that has been reported in hepatocytes and bile duct epithelia of chronic HEV patients seems to indicate that HEV causes bile duct injury [31].

Importantly, this study represents an attempt to identify risk factors for autoantibody positivity in patients with acute HEV infection. Our results showed that the prevalence of autoantibodies increases with age, which may reflect cumulative exposure to environmental factors, as in the case of ANA [32, 33]. Notably, high levels of ALP were observed in acute HEV patients with autoantibodies. One possible explanation is that liver disease caused by HEV infection may be partly due to bile duct-related immune responses, including autoimmunity [34]. Increased levels of serum IgG and IgM have been shown to be distinctive biochemical features of $\mathrm{AIH}$ and $\mathrm{PBC}$, respectively $[35,36]$. Higher serum $\operatorname{IgE}$ levels were observed to more likely occur in patients with positive autoantibodies at the time of acute HEV infection, and autoantibodies disappeared after HEV clearance. These results suggest that the hypersensitivity reaction initiated by antiviral immunity could be the major cause of the pathologic manifestations of viral disease. As only a few of the total serum Ig levels were determined at follow up, it was difficult to follow the evolution of
Ig titers. As $67 \%$ of the study population was infected with subtype $4 \mathrm{~d}$, no significant association between HEV genotype and evolution of autoantibodies was observed. Our study and that of Wu et al. [21] identified completely different risk factors for autoantibody positivity. This might have been caused by different clinical phenotypes of acute HEV infection in the two cohorts. For example, there were more aminotransferases and less bilirubin in the present cohort compared to that of $\mathrm{Wu}$ et al.

This study had several limitations. Firstly, the current study, as for Terziroli et al. [19] and Wu et al. [21], did not incorporate a control group to compare background levels of autoantibodies, e.g., age- and sex-matched healthy controls. Secondly, the autoantibody-negative patients at presentation were not followed up, which introduces potential bias when examining longitudinal changes in autoantibodies, since it remains unclear if those patients developed autoantibodies after clearing HEV. Recently, one study of HCV reported that $27 \%$ of those who were negative pre-treatment developed de novo autoantibodies after cure of HCV by direct-acting antiviral agents [6]. Thirdly, the cut-off for IIF on triple rodent tissue used here was 1:100, higher than the one recommended, and the IIF pattern of SMA was unspecified on the records. Therefore, a prospective study with more patients with HEV infection is required to validate longitudinal changes in autoantibodies, especially for those autoantibody-negative patients, using the latest testing standard [2].

In conclusion, our findings indicate that autoantibodies associated with $\mathrm{AIH}$ or $\mathrm{PBC}$ are frequently present during acute HEV infection, indicating that HEV infection should be excluded before diagnosing AIH and/or PBC. Importantly, in some cases, these autoantibodies persist after viral clearance. Further, autoimmune liver disease may be more prominent during extended time periods, since one of our cases developed de novo autoantibodies and progressed to $\mathrm{PBC}$ in the medium-term. Our research suggests that the presence of autoantibodies may be considered as an early warning of preclinical autoimmunity and may identify the need for long-term follow-up.

Code availability Not applicable.

Authors contribution QX and HLG conceived and designed the study; HLG, QL, ZQL, and WJW collected the clinical data; HLG, WJW, and $\mathrm{JL}$ conducted the analysis and prepared the manuscript; JL and QX critically revised the manuscript. All authors approved the final version of the manuscript.

Funding This work was supported by the Shanghai Three-Year Plan of the Key Subjects Construction in Public Health-Infectious Diseases and Pathogenic Microorganism (15GWZK0102), the Shanghai Three-Year Plan of the Clinical Skills and Innovations (16CR1002A), the Shanghai Municipal Key Clinical Specialty (shslczdzk01103), and Key Projects in the National Science and Technology Pillar Program during the Thirteen Five-year Plan Period (2017ZX10203202). 
Data availability The datasets generated and analyzed during the present study are available from the corresponding author on reasonable request.

\section{Declarations}

Ethics approval The study was conducted in accordance with ethical guidelines of the Declaration of Helsinki 1975 and was approved by the ethics committee of Shanghai Ruijin Hospital (No.2019-251). Written informed consent was exempted on account of retrospective nature of this study.

Consent to participate Not applicable.

Consent for publication Not applicable.

Conflict of interest The authors declare that they have no conflict of interest.

Open Access This article is licensed under a Creative Commons Attribution 4.0 International License, which permits use, sharing, adaptation, distribution and reproduction in any medium or format, as long as you give appropriate credit to the original author(s) and the source, provide a link to the Creative Commons licence, and indicate if changes were made. The images or other third party material in this article are included in the article's Creative Commons licence, unless indicated otherwise in a credit line to the material. If material is not included in the article's Creative Commons licence and your intended use is not permitted by statutory regulation or exceeds the permitted use, you will need to obtain permission directly from the copyright holder. To view a copy of this licence, visit http://creativecommons.org/licenses/by/4.0/.

\section{References}

1. Sebode M, Weiler-Normann C, Liwinski T, Schramm C. Autoantibodies in autoimmune liver disease-clinical and diagnostic relevance. Front Immunol. 2018;9:609. https://doi.org/10.3389/ fimmu.2018.00609.

2. Terziroli Beretta-Piccoli B, Mieli-Vergani G, Vergani D. Serology in autoimmune hepatitis: a clinical-practice approach. Eur J Intern Med. 2018;48:35-43. https://doi.org/10.1016/j.ejim.2017.10.006.

3. Terziroli Beretta-Piccoli B, Mieli-Vergani G, Vergani D, Vierling JM, Adams D, Alpini G, et al. The challenges of primary biliary cholangitis: what is new and what needs to be done. J Autoimmun. 2019;102328:102328. https://doi.org/10.1016/j.jaut.2019.102328.

4. Christen U, Hintermann E. Pathogens and autoimmune hepatitis. Clin Exp Immunol. 2019;195(1):35-51. https://doi.org/10.1111/ cei.13203.

5. van Gemeren MA, van Wijngaarden P, Doukas M, de Man RA. Vaccine-related autoimmune hepatitis: the same disease as idiopathic autoimmune hepatitis? Two clinical reports and review. Scand J Gastroenterol. 2017;52(1):18-22. https://doi.org/10.1080/ 00365521.2016 .1224379 .

6. Terziroli Beretta-Piccoli B, Di Bartolomeo C, Deleonardi G, Grondona AG, Silvestri T, Tesei C, et al. Autoimmune liver serology before and after successful treatment of chronic hepatitis $\mathrm{C}$ by direct acting antiviral agents. J Autoimmun. 2019;102:89-95. https://doi.org/10.1016/j.jaut.2019.04.019.

7. Marconcini ML, Fayad L, Shiozawa MB, Dantas-Correa EB, Lucca Schiavon L, Narciso-Schiavon JL. Autoantibody profile in individuals with chronic hepatitis C. Rev Soc Bras Med Trop.
2013;46(2):147-53. https://doi.org/10.1590/0037-8682-00392013.

8. Liver. EAftSot. EASL Clinical Practice Guidelines on hepatitis E virus infection. J Hepatol. 2018;68(6):1256-71. https://doi.org/10. 1016/j.jhep.2018.03.005.

9. Horvatits T, Schulze Zur Wiesch J, Lutgehetmann M, Lohse AW, Pischke S. The clinical perspective on hepatitis E. Viruses. 2019;11(7). https://doi.org/10.3390/v11070617.

10. Chauhan A, Webb G, Ferguson J. Clinical presentations of Hepatitis E: a clinical review with representative case histories. Clin Res Hepatol Gastroenterol. 2019;43:649-57. https://doi.org/ 10.1016/j.clinre.2019.01.005.

11. Krzowska-Firych JM, Lucas C, Lucas G, Tomasiewicz K. Hepatitis E - a new era in understanding. Ann Agric Environ Med. 2018;25(2):250-4. https://doi.org/10.26444/aaem/75142.

12. Narayanan S, Abutaleb A, Sherman KE, Kottilil S. Clinical features and determinants of chronicity in hepatitis $\mathrm{E}$ virus infection. J Viral Hepat. 2019. https://doi.org/10.1111/jvh.13059.

13. Pischke S, Gisa A, Suneetha PV, Wiegand SB, Taubert R, Schlue J, et al. Increased HEV seroprevalence in patients with autoimmune hepatitis. PLoS One. 2014;9(1):e85330. https://doi.org/10.1371/ journal.pone.0085330.

14. Eder M, Strassl R, Beinhardt S, Stattermayer AF, Kozbial K, Lagler $\mathrm{H}$, et al. High seroprevalence of anti-Hepatitis $\mathrm{E}$ antibodies in Austrian patients with autoimmune hepatitis. Liver Int. 2019;39(4):640-5. https://doi.org/10.1111/liv.14005.

15. van Gerven NM, van der Eijk AA, Pas SD, Zaaijer HL, de Boer YS, Witte BI, et al. Seroprevalence of hepatitis E virus in autoimmune hepatitis patients in the Netherlands. J Gastrointest Liver Dis. 2016;25(1):9-13. https://doi.org/10.15403/jgld.2014.1121.251.hpe.

16. Vieira CL, Baldaia C, Fatela N, Ramalho F, Cardoso C. Case of acute hepatitis $\mathrm{E}$ with concomitant signs of autoimmunity. World $\mathrm{J}$ Hepatol. 2013;5(3):152-5. https://doi.org/10.4254/wjh.v5.i3.152.

17. Patel I, Ching Companioni R, Bansal R, Vyas N, Catalano C, Aron $\mathrm{J}$, et al. Acute hepatitis E presenting with clinical feature of autoimmune hepatitis. J Commun Hospit Int Med Perspect. 2016;6(6): 33342. https://doi.org/10.3402/jchimp.v6.33342.

18. Minkoff NZ, Buzzi K, Williamson AK, Hagmann SHF. Case report: acute hepatitis $\mathrm{E}$ in a pediatric traveler presenting with features of autoimmune hepatitis: a diagnostic and therapeutic challenge. Am J Trop Med Hyg. 2019;100(1):155-8. https://doi.org/10. 4269/ajtmh.18-0640.

19. Terziroli Beretta-Piccoli B, Ripellino P, Gobbi C, Cerny A, Baserga A, Di Bartolomeo C, et al. Autoimmune liver disease serology in acute hepatitis E virus infection. J Autoimmun. 2018;94:1-6. https://doi.org/10.1016/j.jaut.2018.07.006.

20. Monteserin Ron L, Jimenez Palacios M, Linares Torres P, Miguel Pena A, Alvarez Cuenllas B, Fernandez-Natal MI, et al. Autochthonous acute hepatitis E: an increasingly frequent diagnosis. Clinical-epidemiological analysis of our experience. Revista espanola de enfermedades digestivas. 2017;109(5):344-9. https:// doi.org/10.17235/reed.2017.4258/2016.

21. Wu J, Guo N, Zhu L, Zhang X, Xiong C, Liu J, et al. Seroprevalence of AIH-related autoantibodies in patients with acute hepatitis E viral infection: a prospective case-control study in China. Emerg Microb Infect. 2020;9(1):332-40. https://doi.org/ $10.1080 / 22221751.2020 .1722759$.

22. Sylvan SP, Hellstrom UB, Hampl H, Kapprell HP, Troonen H. Hepatitis $\mathrm{E}$ in patients with chronic autoimmune liver disease. Jama. 1995;273(5):377-8. https://doi.org/10.1001/jama.1995. 03520290029022.

23. Le Cann P, Tong MJ, Werneke J, Coursaget P. Detection of antibodies to hepatitis $\mathrm{E}$ virus in patients with autoimmune chronic active hepatitis and primary biliary cirrhosis. Scand J Gastroenterol. 1997;32(4):387-9. https://doi.org/10.3109/ 00365529709007689 . 
24. Kanda T, Yasui S, Nakamura M, Arai M, Sasaki R, Haga Y, et al. Recent trend of hepatitis E virus infection in Chiba Area, Japan: 3 of 5 cases with rheumatoid arthritis. Case Rep Gastroenterol. 2015;9(3):317-26. https://doi.org/10.1159/000441387.

25. Corpechot C, Chazouilleres O, Poupon R. Early primary biliary cirrhosis: biochemical response to treatment and prediction of long-term outcome. J Hepatol. 2011;55(6):1361-7. https://doi.org/ 10.1016/j.jhep.2011.02.031.

26. Leung PS, Rossaro L, Davis PA, Park O, Tanaka A, Kikuchi K, et al. Antimitochondrial antibodies in acute liver failure: implications for primary biliary cirrhosis. Hepatology. 2007;46(5):143642. https://doi.org/10.1002/hep.21828.

27. Cozzani E, Drosera M, Riva S, Parodi A. Analysis of a multiple nuclear dots pattern in a large cohort of dermatological patients. Clin Lab. 2012;58(3-4):329-32.

28. Muratori P, Muratori L, Cassani F, Terlizzi P, Lenzi M, Rodrigo L, et al. Anti-multiple nuclear dots (anti-MND) and anti-SP100 antibodies in hepatic and rheumatological disorders. Clin Exp Immunol. 2002;127(1):172-5. https://doi.org/10.1046/j.13652249.2002.01719.x.

29. Sun C, Xiao X, Yan L, Sheng L, Wang Q, Jiang P, et al. Histologically proven AMA positive primary biliary cholangitis but normal serum alkaline phosphatase: is alkaline phosphatase truly a surrogate marker? J Autoimmun. 2019;99:33-8. https:// doi.org/10.1016/j.jaut.2019.01.005.

30. Tanaka A. Anti-mitochondrial autoantibodies-milestone or byway to primary biliary cholangitis? Ann Translat Med. 2017;5(3):50. https://doi.org/10.21037/atm.2017.01.42.
31. Beer A, Holzmann H, Pischke S, Behrendt P, Wrba F, Schlue J, et al. Chronic Hepatitis $\mathrm{E}$ is associated with cholangitis. Liver Int. 2019;39(10):1876-83. https://doi.org/10.1111/liv.14137.

32. Fernandez SA, Lobo AZ, Oliveira ZN, Fukumori LM, Pr AM, Rivitti EA. Prevalence of antinuclear autoantibodies in the serum of normal blood donors. Revista do Hospital das Clinicas. 2003;58(6):315-9. https://doi.org/10.1590/s0041-87812003000600005.

33. Racoubian E, Zubaid RM, Shareef MA, Almawi WY. Prevalence of antinuclear antibodies in healthy Lebanese subjects, 2008-2015: a cross-sectional study involving 10,814 subjects. Rheumatol Int. 2016;36(9):1231-6. https://doi.org/10.1007/s00296-016-3533-0.

34. Wedemeyer H, Rybczynska J, Pischke S, Krawczynski K. Immunopathogenesis of hepatitis E virus infection. Semin Liver Dis. 2013;33(1):71-8. https://doi.org/10.1055/s-0033-1338118.

35. European Association for the Study of the L. EASL Clinical Practice Guidelines: autoimmune hepatitis. J Hepatol. 2015;63(4): 971-1004. https://doi.org/10.1016/j.jhep.2015.06.030.

36. European Association for the Study of the Liver. Electronic address eee, European Association for the Study of the L. EASL Clinical Practice Guidelines: the diagnosis and management of patients with primary biliary cholangitis. J Hepatol. 2017;67(1):145-72. https:// doi.org/10.1016/j.jhep.2017.03.022.

Publisher's note Springer Nature remains neutral with regard to jurisdictional claims in published maps and institutional affiliations. 